\title{
¿Es posible una teoría del conocimiento en Miguel de Unamuno?
}

Luisa Montaño Montero Universidad de Sevilla, España

Resumen

¿Es posible hablar de una teoría del conocimiento en Miguel de Unamuno? Responder a esta pregunta nos exige recorrer su obra para encontrar sus ideas en torno al problema, pues nunca planteó una epistemología explícita. Su concepción de la razón, considerada como algo más que en su aspecto lógico-matemático, condicionará su visión del conocimiento. Al reconocerle un aspecto histórico y vital la abrirá a otros modos de realidad inaccesibles a la razón pura. Si el mundo cambia, la razón ha de modificarse a su vez para conocerlo. La "intuición” y el "lenguaje” serán los instrumentos para acceder a esas realidades. Ambos conceptos estarán fundamentados en su idea de hombre como esencialmente mutable e histórico. Por tanto, Unamuno se insertó en una tradición filosófica en la que cobraban valor aspectos hasta entonces olvidados.

Palabras clave: Unamuno, conocimiento, razón, empatía, realidad.

\section{Abstract}

Is it possible to find in Unmanuno's a Knowledge's theory? Answer this question demand us to examine his work to find his ideas about the problema because he never poses an explicit epistemology. He had a concepcion of reason as something more than the logical-rational aspect and this point of view knowledge condition affect his view of 
knowledge. He admit that reason have a historic and vital aspect and their make possible to know other modes of reality inaccessible to pure reason. Intuition and language are tools to understand the world, all of which, based on an idea of man characterized by its history and change, and in which to insert this new way of understanding the reason as also affected by the time. And with them, an approach to truth as essential to life.

Keywords: Unamuno, Knowledge, Reason, Empathy, Reality.

\section{$\mathrm{E}$} 1 siguiente trabajo tratará de analizar las ideas unamunianas en torno a la teoría del conocimiento. Todo aquel que conozca mínimamente su pensamiento sabrá que no vamos a encontrar un tratado específico acerca de este problema, por tanto, sólo hemos de rastrear su obra para hallar en ella sus ideas y opiniones. Partiendo, pues, de la inexistencia en Miguel de Unamuno de una epistemología explícita, nos encontramos con un primer acercamiento a la cuestión cuando afirma que "pretender definir el conocimiento es pretender definir la definición, es como buscar la causa de la causa, la sustancia de la sustancia o la realidad de la realidad" (Unamuno, 1916: 1084).

Como vemos, su misma posición de salida es problemática, puesto que no admite, ni siquiera, definir lo que sea o señalar en qué consiste el conocimiento. Tradicionalmente se ha definido el conocimiento como el acto de aprehender un sujeto o un objeto. Dos son los términos que destacan en esta definición: la existencia, por una parte, de un sujeto que conoce; y por otra, la de un objeto que es conocido. La relación y el estatus de cada uno de ellos van a condicionar una posible caracterización del conocimiento y del conocer. Si prima el objeto, entonces hablamos de realismo, si es el sujeto entonces nos referimos al idealismo. Si no se admite la primacía de ninguno de ellos, sino que se equiparan ambos términos, entonces estamos ante la fenomenología. 
Sin embargo, el aspecto que Unamuno destaca cuando habla de cómo el hombre conoce es aquel que se refiere a una condición específica de la razón, y es su capacidad para conocer otras realidades que se le escapa a una razón pura. En este sentido, estaríamos hablando de que el acto de conocimiento se realiza mediante la empatía (endopatía), entendida como una especie de participación afectiva de un sujeto en una realidad que le es ajena. Esta acción puede aplicarse a diversos aspectos, como objetos del contorno familiar, procesos de fenómenos naturales, ideas, etcétera. Pero también puede tener diversas características, pues puede ser algo consciente o inconsciente, intencional o no, etcétera. De lo que no cabe duda es que mediante la empatía el sujeto llega a tener un conocimiento más profundo de ciertos fenómenos o procesos que están fuera de él (Ferrater, 2005: 1008). Con esto se otorga cierto estatus de verdad a un conocimiento de la realidad no mediado por la razón. Unamuno se situaría en esta línea de pensamiento. Es evidente la gran complejidad que existe en todo proceso cognoscitivo realizado por el hombre, concepción que se articularía perfectamente con el pensamiento unamuniano y con su forma de considerar la filosofía como una disciplina que no sólo reparaba en las realidades accesibles mediante la razón.

Tradicionalmente se ha concebido a la razón como absoluta y eterna, existiendo la primacía del razonamiento lógico-racional, caracterizado por un discurso deductivo en el que siguiendo una serie de reglas lógicas se puede obtener la verdad. Sin embargo, la razón, al igual que el hombre, ha de ser histórica, cambiante, del mismo modo que lo es la realidad. Además, el discurso lógicoracional se caracteriza por ser anónimo y ahistórico. Frente a éste se situaría el discurso patético, en el que ni la situación histórica ni el orador son reemplazables, por lo que siempre es particular y concreto. Es el conflicto entre el concepto y la palabra, pues el primero es abstracto y universal, mientras que el segundo es concreto 
y particular. Lo que ha ocurrido es que estos dos tipos de discurso se han separado, imponiéndose el primero, y siendo arrinconado y tachado de irracional y no científico el segundo.

Pues bien, todo esto se intuye en el pensamiento unamuniano, tal y como hemos tratado en otro lugar (Montaño y Sánchez, 2006: 377-386). Para Unamuno era un hecho irrefutable que la realidad cambiaba, fluía, tal y como ya decía Heráclito en los albores del pensamiento. Esto va a significar la imposibilidad de mantener una concepción de la razón tan absoluta. Según esta tradición, la razón establecería una serie de verdades e ideas inmutables que quedarían fijadas ya desde los orígenes, de modo que la realidad debe ser desvelada desde ellas, debiéndose amoldar a esos conceptos. Pero Unamuno pensaba que:

[...] el hombre es espíritu, lo humano es lo espiritual, y la vida del espíritu es la historia y todo lo demás, lo natural, no es más que la base, el lugar más bien, el dónde de lo histórico [...] la vida es, ante todo, vida espiritual, es decir, humana, y la vida espiritual es vida histórica, que es la historia de la vida del Espíritu humano en lo colectivo (1917: 1195).

El hombre mismo es una realidad histórica que construye todo lo que hay, incluso las ciencias, motivo por el que ella misma, la razón, es historia y, por tanto, susceptible de adoptar distintos modos según la época. Si consideramos que la historicidad es lo más propio del hombre, entonces sería absurdo proponer una razón inmutable que dé sentido a la realidad. Es imposible defender una razón de este tipo como garante del conocimiento científico, pues si la realidad se va transformando será incapaz de ir desvelándola y mostrándola, puesto que los conceptos que debe aplicar serán insuficientes para reflejar los cambios que se originan. Juan Luis Vives, en De prima philosophia, se había percatado de la necesidad de reconocer la historicidad del lenguaje para poder adecuarse a la naturaleza. 
Conforme a esto, será necesario un lenguaje que pueda explicar ese cambio constante, y que lo exprese mediante la palabra. Porque la ciencia no es el único modo de conocer el mundo, ya que hay realidades que no son cognoscibles al modo científico, y esto no ha de significar que no existan. Tan sólo hemos acceder a ellas con otro método que no es el racional científico. Ésta sería la tradición retórica, en la que se insertaría, en cierto modo, Unamuno.

Partiendo, pues, de esta problemática sobre los distintos modos de razón, Unamuno creía que era erróneo considerar que sólo la razón científica podía tener acceso al conocimiento de la realidad y concebirla como un mero clasificar, ya que esto suponía despojarlo de su origen intuitivo (Unamuno, 1991: 63). Cuando hablamos de intuición nos referimos a la visión directa e inmediata que tenemos de la realidad, de manera que tendríamos un conocimiento primario y fundamental de ella, y no serían necesarios intermediarios. En cambio, el conocimiento deductivo operaría con los conceptos y el razonamiento. En este sentido, es interesante el artículo de José Manuel Serrano (1994: 143-167), donde podemos ver el análisis comparativo entre el pensamiento de Unamuno y el de Descartes. Este artículo parte de la idea cartesiana de que el pensamiento es el único que puede conducirnos hacia la evidencia de la verdad. Sin embargo, la duda será condición necesaria para que, mediante el método, podamos alcanzar un conocimiento deductivo válido e irrefutable de la realidad. La verdad sería entonces caracterizada como apodíctica, en la que la claridad y la distinción habrían de ser los criterios de verdad (Descartes, 1997: 145-146). Éste sería el nuevo método de la ciencia, y el que habríamos de seguir si queremos llegar a alguna verdad. No obstante, Unamuno no estará de acuerdo con Descartes y su máxima cogito, ergo sum. No cree que sea el puro pensamiento el que fundamente y dirija la vida del hombre, y aboga por la primacía del sum sobre el cogito (Descartes, 1997: 146). Creía que 
lo primero no era el pensar, sino el vivir, puesto que los que no piensan también viven, aunque este último no fuese un verdadero vivir. Es el problema de querer conciliar la razón con la vida (Unamuno, 1913a: 130), pues para él existía una oposición tal que "todo lo vital es antirracional, no ya sólo irracional, y todo lo racional, antivital. Y esta es la base del sentimiento trágico de la vida" (Unamuno, 1913a: 129).

Pero continuando con su crítica a Descartes, en Unamuno el ser cobra importancia con respecto al pensamiento, pues de otro modo creía que se cercenaba la compleja realidad del hombre. Bajo este entendido, distinguía entre racionalismo y vitalismo:

\begin{abstract}
[...] los racionalistas buscan la definición y creen en el concepto, y los vitalistas buscan la inspiración y creen en la persona. Los unos estudian el Universo para arrancarle sus secretos; los otros rezan a la Conciencia del Universo, tratan de ponerse en relación inmediata con el Alma del mundo, con Dios, para encontrar garantía o sustancia a lo que esperan, que es no morirse, y demostración de lo que no ven (Unamuno, 1913a: 221-222).
\end{abstract}

Su crítica al racionalismo pasa por la idea de que esta razón deja fuera lo que llama "el enigma de la ultimidad", es decir, el problema de la fe y de la trascendencia. La razón mata a la fe, pues ella no puede fundamentar una certeza sobre la trascendencia del hombre. Y es que:

$\mathrm{Ni}$ el sentimiento logra hacer del consuelo verdad, ni la razón logra hacer de la verdad consuelo; pero esta segunda, la razón, procediendo sobre la verdad misma, sobre el concepto mismo de realidad, logra hundirse en un profundo escepticismo. Y en este abismo encuéntrase el escepticismo racional con la desesperación sentimental, y de este encuentro es de donde sale una base - iterrible base!— de consuelo (Unamuno, 1913a: 171). 
Pues bien, para Unamuno el inconveniente de la razón (deductiva) es que tiende a lo muerto, diciendo que el pensamiento que no se renueva muere (Unamuno, 1914: 309), ya que lo vivo se le escapa, puesto que es extraordinariamente difícil apresar en conceptos la vida, lo que termina siendo una tragedia, la lucha de la razón con la vida por intentar abrirse a ella (Unamuno, 1913a: 162). De este modo, ha demostrado que la razón lógico-matemática queda fuera de todo posible conocimiento verdadero, ya que se le escapa el aspecto más esencial del hombre. No creía en la posibilidad de conocimiento objetivo característico de la ciencia:

A mí, debo declararlo, me divierte mucho todo eso de lo objetivo, de lo científico, de la definición, etc. Sobre todo, esto de la definición. Y como las cosas concretas, reales, individuales, son indefinibles y sólo se definen los conceptos abstractos, no me apura mucho eso de la definición. Sé que pueden definir un tetraedro o un cubo o un tintero, pero sé que no pueden definir este tintero que tengo yo ahora delante de mí. Se que pueden definir, mejor o peor, al hombre, pero sé que no pueden definirme, ni bien ni mal, a mí concretamente. Sé, en fin, que si la definición es base de la ciencia, la indefinición es la base de la sabiduría. Y todo el respeto que por la ciencia siento [...] se me convierte en desdén cuando del cientificismo se trata [...]. Yo también profeso una ciencia, la filología, de métodos rigurosos, de precisas definiciones, pero no se me ocurre confundir la filología con el lenguaje, y sé que en este hay mucho de indefinible, de concretamente vivo (Unamuno, 1909: 189).

Frente a la definición de lo universal, la indefinición de lo real. El universal no tiene validez para Unamuno, pues lo que le preocupa es lo concreto. No puede ser de otro modo, ya que lo que le interesa es el hombre de carne y hueso, o sea, el hombre concreto (Unamuno, 1913a: 109). Definir algo significa delimitar intelectualmente lo que sea ese algo, es decir, su esencia, tal y como ya 
decía Aristóteles: “[...] saber cada cosa equivale a saber su esencia” (1975: 153). La definición como método de conocimiento tiene en Sócrates a su mayor exponente, a través, por supuesto, de su discípulo Platón. En sus diálogos, el método a seguir era el siguiente: se comenzaba planteando un problema, y a través de las preguntas de Sócrates se iba alcanzando una definición del concepto buscado, generalmente de carácter moral o religioso. De las respuestas de los interlocutores se iba consiguiendo una serie de definiciones que daban lugar a una única formulación, y que finalmente era sometida a crítica (Guthrie, 1990: 75). Con este método inductivo lo que se buscaba era el elemento común de los distintos casos expuestos, de manera que se llegaba a la caracterización del universal en ellos. Sin embargo, para Unamuno esto carecía de valor, puesto que al final lo que tendríamos sería un concepto abstracto, y a él le interesaba lo concreto. Distinguía entre lenguaje común, que sería el del sentido común, caracterizado por referirse a las necesidades prácticas de la vida del hombre y por no buscar la precisión al modo de la ciencia. Frente a éste, el lenguaje científico, cuya primera tarea es crear una lengua propia, una especie de álgebra, dirá Unamuno. Es la paradoja como lo contrario al sentido común, en tanto que éste se caracteriza por lo colectivo, lo general, mientras aquélla es el producto del sentido propio, haciendo posible el progreso, pues éste sólo ocurre desde lo individual (Unamuno, 1910b: 551).

Ahora bien, como decíamos antes, Unamuno apuntaba que "el pensamiento es cosa fluida, es curso de ideas — que cambian ¡claro! - es vida. En cuanto se llega al dogma se deja de pensar. Un dogma se aprende y se repite; pero no se piensa. En cuanto se piensa un dogma, el dogma se deshiela, se funde, se va" (Urrutia, 2006: 263). Es decir, el pensamiento como algo que constantemente está cambiando, y frente a él están las ideas como algo sólido, cuajado, afirmando que el pensamiento disuelve la idea (Unamuno, 1921: 
454). Es la primacía del pensamiento (lo vivo) sobre las ideas (lo muerto).

Esta visión se integra dentro de una filosofía de la vida en la que lo distintivo del hombre y del mundo era precisamente el cambio, la historicidad, y por ello se reafirmaba la necesidad de una razón viva capaz de dar cuenta de esta realidad cambiante. Como consecuencia atacará a todo dogmatismo, a toda ciencia que pretenda erigirse como la poseedora de todas las verdades, ya que el conocimiento si no se ejerce de forma crítica sólo lleva al individuo, a asumir una serie de ideas sin una reflexión previa. Es lo que llamaba la "fe de carbonero", que consistía en delegar en otros, de forma que fuesen ellos quienes pensasen por nosotros (Núñez y Ribas, 1911: 187). Los individuos tienden a admitir las opiniones de los demás sin un examen crítico, aceptándolas como verdades probadas y libres de sospecha (Unamuno, 1936: 1144). Ésta era la actitud que había que evitar, y por ello establecía como requisito imprescindible en el conocimiento la exigencia de que cada uno de nosotros realizase un análisis de la información que recibiese para comprobar que, en efecto, era verdadera. Su intención era, por un lado, que fuésemos lo suficientemente reflexivos como para saber distinguir lo verdadero de lo falso, y por otro lado, la necesidad de no depender de nuestras ideas, de no esclavizarnos a ellas, puesto que "las ideas deben tenerse mientras sirve y sustituirse después con otras nuevas. Hago con ellas lo que con los zapatos: las uso mientras están útiles; luego las tiro; nunca falta quien las recoja" (Unamuno, 1903a: 98). Nada más contraproducente para el hombre que verse esclavizado por las ideas, ya que ello traía consigo una terrible consecuencia: el obligarnos a seguirlas aun cuando estuvieses en desacuerdo con ellas. En un mundo que se caracteriza por la historicidad y el cambio, someterse a la dictadura de unas opiniones fijas e inmutables era impensable para Unamuno, puesto que si el mundo avanza, muta, entonces es lógico que las ideas 
sobre él tengan que adaptarse (cambiar) para ser capaces de seguir explicándolo.

Pero, ¿cómo caracterizaba el conocimiento Unamuno? Decía que conocer era clasificar, y que la ciencia era la generalización e integración del conocimiento. Las ideas se iban reduciendo a ideas más generales, de modo que explicar un hecho consistía en referirlo a otros hechos, a generalizarlo (Unamuno, 1886: 128). En otro momento, señalaba:

[...] conocer una cosa es clasificarla, es decir, darle un nombre. El conocimiento es clasificación que crece en extensión e intensidad. El hombre ignorante sólo sabe el nombre propio de las cosas, su nombre de pila pero desconoce su apellido. La ciencia consiste en ir conociendo sus apellidos, el primero, el segundo, etc.; Cuanto más adelantemos en la ciencia más apellidos sabemos darle, y colocarle en la misma familia que los que tienen el mismo apellido, trazar su genealogía. En los nombres simbolizamos y encerramos nuestra ciencia (Unamuno, 1998: 181).

Expresa aquí la esencial relación existente entre mundo y lenguaje, considerando que el conocer la realidad comienza al nombrar a los entes que allí encontramos, y para esto será necesario el uso del lenguaje. ¿Qué era la realidad o lo real para Unamuno? El vocablo "realidad" deriva de real, y éste a su vez de res, cosa. Pensaba que, generalmente, frente a lo real se contraponía lo ideal, esto es, frente a la realidad la idealidad. Sin embargo, se cuestionaba el hecho de que se tuviesen a las ideas como menos reales que las cosas, por lo que afirmaba que ellas eran incluso más verdaderas, pues duraban más que las cosas (Unamuno, 1923a: 503). Con esto admitía una cierta gradación ontológica, y reconocía la existencia de distintas clases de realidades que podían ser conocidas, además, mediante el lenguaje. 
Lenguaje, hombre y mundo van indisolublemente unidos, sólo en esa triple relación adquiere sentido el conocimiento (Unamuno, 1998: 181). Por esta razón, obra un valor primordial el lenguaje, pues es el que crea el mundo, y será "el instrumento de la acción espiritual, es la sangre del espíritu” (Núnez y Ribas, 1923: 423). Asemeja esto a la creación del mundo, tal y como se recoge en el Génesis, cómo Dios mediante la Palabra creó el mundo, y cómo después le presentó al hombre todas las criaturas del mundo para que éste les diera un nombre (Unamuno, 1906c: 151). Hay una interacción entre el hombre y el mundo, y el lenguaje es su instrumento. Por tanto, en ese crear que supone el lenguaje cobra especial interés el hombre, pues él es el encargado de realizar semejante tarea.

Unamuno afirmará que "conocer es, en efecto, engendrar, y todo conocimiento vivo supone la penetración, la fusión de las entrañas del espíritu que conoce y de la cosa conocida" (Unamuno, 1931: 324). Hay una profunda interrelación entre el sujeto cognoscente y la cosa conocida, relación que debe partir siempre del sujeto que tiene que buscar desde lo particular lo universal (Unamuno, 1913b: 303). En este sentido, podemos decir que para Unamuno todo conocimiento ha de comenzar con los sentidos, de lo concreto, tal y como antes hemos señalado. Para él, lo que conocemos del mundo es lo que ponemos en él, en tanto estamos contenidos en la realidad que tratamos de conocer. Por ello, creía que era falso el principio de que, como observadores, podíamos desentendernos de lo observado (Unamuno, 1900: 197). El problema de este conocimiento es que nos encontramos con un yo que nos ha hecho el mundo o, más bien, que nosotros hemos construidos al esclavizarnos en él. Con esto, no somos capaces de ver fuera de él "la inmensa esplendidez del cielo y la terrible realidad de la muerte, tener que ser lógicos dentro de él" (Unamuno, 1970: 822). De este modo, nos muestra Unamuno cómo a 
veces el hombre termina siendo el siervo de una realidad que nos conforma a su imagen y semejanza, dejando de lado lo que verdaderamente le importa al hombre, y que no puede ser abordado desde la mera razón.

En esta concepción del conocimiento sobresale la exigencia de que éste esté al servicio de la vida del hombre, aunque también va a distinguir otro tipo de conocimiento subordinado a aquel. Este segundo modo se caracterizará por ser un conocimiento de lujo, y se correspondería con ese deseo de conocer la curiosidad que sólo nace si se han cubierto, primero, las necesidades más inmediatas del hombre. Sin embargo, este segundo tipo nunca será un conocimiento desinteresado, un mero conocer contemplativo, puesto que siempre tendrá como objetivo la búsqueda de la vida en la verdad (Unamuno, 1913a: 123).

Por tanto, establecerá dos tipos de conocimiento: uno primario y otro secundario. El primario, que sería inevitable para que el hombre pueda sobrevivir, y que se vincularía con la exigencia del vivir humano y el instinto de conservación, y que a su vez habría generado en todo hombre los órganos necesarios para el conocimiento. Este conocimiento primario respondería sólo a la necesidad del individuo de sobrevivir, por lo que todo ser humano participaría de él. Dirá que este conocer es el que nos muestra aquello que necesitamos para subsistir, de modo que es el instinto de conservación el que nos hace la realidad y la verdad del mundo perceptible. Esto deja el camino abierto para la admisión de otras realidades que no percibimos porque al no sernos necesarias para vivir no nos percatamos de ellas (Unamuno, 1913a: 122-124). Este juicio de Unamuno guarda estrecha relación con la interpretación del ingenio en Vico según Grassi, puesto que:

[...] sólo 'humanizamos' la naturaleza cuando vemos los fenómenos que nos ofrecen los sentidos en su relación con nuestras necesidades y con la realización de nuestra existencia. Por eso, para 
Vico es el ingenio y no la razón quien fundamenta el surgimiento del mundo humano (Grassi, 2003: 218-219).

El hombre sólo repara en aquello que le ayuda a vivir, siendo ciego a las cosas inútiles, lo cual no significa que en el mundo sólo exista lo que vemos. Puede ocurrir que haya otra realidad invisible a los ojos humanos, y ello no supondrá su inexistencia.

Sin embargo, el conocimiento secundario estaría ligado al instinto de perpetuación, que nos alejaría del aislamiento individual y nos pondría en relación con los otros. Éste es fundamental, ya que es esencial en el ser humano el ser miembro de una sociedad, pues sólo de ella brotará la razón (conocimiento reflexivo y reflejo).Este conocimiento, por tanto, sería el que nos permitiría la vida en sociedad. Y es que para Unamuno el pensamiento y la razón tienen su origen en la sociedad (Núñez y Ribas, 1902: 180). Para él, esta razón (social) se origina en el lenguaje.

\section{Lenguaje, conocimiento y mundo: vinculos y relaciones}

Para Unamuno, el lenguaje tenía una gran trascendencia en el problema del conocimiento, en tanto lo consideraba como la herramienta capaz de crear el mundo del hombre, permitiendo no sólo conocerlo sino, además, vivir en él. En el hombre, el pensamiento se da gracias al lenguaje articulado, ya que nos es necesario para vivir y poder expresar lo que pensamos sobre el prójimo (Unamuno, 1913a: 124; 1906a: 879). Lenguaje y pensamiento:

[...] van indisolublemente unidos, puesto que son en el fondo una sola y misma cosa. No cabe pensar sino con palabras y toda palabra supone pensamiento. El pensamiento y el lenguaje se hacen mutuamente, y así, decir que para cada pueblo el mejor idioma es aquel en que se encarna su pensamiento, equivale a de- 
cir que para cada pueblo el mejor pensamiento es el suyo propio (Unamuno, 1902b: 1047).

El lenguaje es el instrumento primordial no sólo para comunicarnos con el otro, sino también para alcanzar el mundo, porque nos permitirá aprehenderlo. Para Unamuno, el lenguaje era una "fuente de riqueza espiritual y hasta económica" (Urrutia, 2006: 231), el instrumento de la acción espiritual (Urrutia, 2006: 232), la sangre del espíritu, su esencia. Para nuestro pueblo, el castellano es el que asume esa misión, el que nos permite no sólo pensar, sino sentir y obrar, destacando, además, que la acción va indisolublemente unida al lenguaje, puesto que sin él se queda en mero gesto, vacío (Nuñez y Ribas, 1902: 183).

Hay un conflicto interno en el hombre por dar a conocer su pensamiento al otro, ya que al hacerlo debe atenerse a la palabra e intentar encontrar el modo de enunciarlo, siendo aquí donde estriba la complicación (Unamuno, 1907c: 399). Hallar la manera de formular nuestro pensamiento mediante las palabras exactas que lo expresen es una ardua tarea. No obstante, al hacerlo conseguimos que esos conceptos a que hemos llegado se nos aclaren y nos permitan una mejor expresión de nuestro pensamiento (Unamuno, 1902a: 206). Afirmaba Unamuno:

[...] he sido muy hablador porque he necesitado hablar mi pensamiento para adquirir propia conciencia plena de él, y porque la palabra material me excitaba a pensar. Pensaba en voz alta. Haciendo esfuerzos por transmitir a otros mis ideas, me las formulaba y descubría a mí mismo y las desarrollaba (Unamuno, 1986: 38-39).

Es el intento por clarificar y depurar el pensamiento, y por lograr perfeccionar la relación entre pensamiento, mundo y lenguaje. En este expresarlo mediante el lenguaje oral se advierte, además, la 
existencia del componente social, no sólo por la necesidad de hacernos entender, sino por la exigencia de ser entendidos por los demás, y de ahí, el imperativo que nos obliga a tener que expresarnos de modo comprensible. Por tanto, tenemos que el pensamiento depende del lenguaje, en tanto que pensamos con palabras; además, le otorga al lenguaje un rasgo del que no puede desprenderse puesto que el pensamiento también lo es (Unamuno, 1907c: 400). Dirá Unamuno:

[...] el lenguaje de que me sirvo para vestir mis sentimientos y mis ideas es el lenguaje de la sociedad en que vivo, es el lenguaje de aquellos a quienes me dirijo; las imágenes mismas, los conceptos en que vierto su savia, son las imágenes y conceptos de los que me oyen; pero la savia, esa savia vivificante que desde las raíces sube a mis frutos, esa savia que no se ve, esa es mía. Y es la que da a mis frutos, la que da a tus frutos, lo que da a los frutos de todo hombre, el sabor que tengan (1906a: 879).

Ese componente social se puede advertir en que en la lengua de cada pueblo se expresa el pensar y el sentir del mismo, pues ella va a constituir lo que Unamuno llama la "sangre del espíritu" (Unamuno, 1915a: 318). La lengua de cada pueblo contiene su alma, y es la forma que hay para conocerse a sí misma y amarse. Conocimiento y comprensión llevan al amor, de ahí se infiere que el desamor (odio) sea causa del desconocimiento que impide la comprensión.

Con lo anterior reconoce la prioridad del uso del lenguaje ordinario, de tener que utilizar las formas de expresión usuales de la sociedad a la que pertenecemos, por ser el modo más preciso de formular nuestro pensamiento. Sin embargo, ello no quiere decir que nos quedemos en ese uso vulgar del lenguaje, sino que lo verdaderamente importante será que al pensar lo hagamos desde nuestro yo más profundo y personal, siendo siempre nuestra 
reflexión algo propio. Por esta razón, el pensamiento ha de ser algo vivo, pues si éste deja de ir transformándose y adaptándose continuamente al mundo y se queda fijo, entonces morirá (Unamuno, 1914b: 309). Unamuno suponía que el pensamiento se extinguiría si se convertía en escritura (Unamuno, 1927: 710). Ésta era la razón por la que daba prioridad al lenguaje hablado frente al lenguaje escrito (Unamuno, 1922: 1467). Al admitir que el lenguaje debía estar al servicio de la vida, y que la vida era esencialmente cambio, era imprescindible plantear la exigencia de que el lenguaje no podía quedar encerrado en conceptos abstractos y lógicos, sino debía ser capaz de dar cuenta de la historicidad de la vida del hombre, adaptándose a las circunstancias concretas de cada momento. Cobra importancia en este contexto la palabra, porque ella será la que recoja fielmente el significado del mundo. Dirá de ella Unamuno:

[...] el misterio de la palabra es que por la palabra, por el verbo, es todo lo que es [...] Que la palabra fue al principio y la palabra será al fin. ¡Deja un nombre! Es todo lo vivo que hay que dejar, un nombre que viva eternamente. Lo demás, son huesos (1932: 1184).

Esta palabra será, esencialmente, metafórica, reconociendo Unamuno que usaba las metáforas como método de conocimiento: “¿Qué ha sido mi constante tendencia a pensar por metáforas, sino la aspiración al misterio? Es que vislumbraba verdades más altas de las que cabe encerrar en fórmulas racionales" (Unamuno, 1986: 39). Tal como hemos apuntado con anterioridad, creía Unamuno en el estrecho vínculo entre poesía y filosofía, entre la palabra poética y la filosófica, de manera que ratificaba que "el discurrir por metáforas es uno de los más naturales y espontáneos, a la vez que uno de los más filosóficos modos de discurrir" (Unamuno, 1904b: 1162). 
El nombre es la cosa, y cuando le asignamos un determinado nombre a una cosa lo que hacemos es conocerla y apropiarnos de ella. El nombre nos permite conocer la cosa, porque al nombrarla la conocemos, además de ser el que transmite el concepto, que en realidad es el nombre socializado (Unamuno, 1903b: 1116-1117). A todo esto hay que unirle el hecho de que el mismo lenguaje es histórico, por lo que con el correr del tiempo los conceptos van variando su significación. Esto supondrá la obligación de tener que desvelar esa transformación que han ido sufriendo para comprenderlos. En cambio, la palabra, al estar referida a lo concreto, permite un conocimiento menos abstracto y más verdadero.

Recapitulando, vemos que el hombre necesita del lenguaje para vivir y para conocer el mundo, y que debe hacer esta tarea de modo individual, pero utilizando los instrumentos que le ofrece la sociedad en que vive. Esto puede traer algunos inconvenientes debido a que la mayoría de la gente suele recurrir al sentido común, es decir, a las frases hechas, al saber popular, sólo porque su pereza intelectual le impide razonar por su cuenta (Unamuno, 1912: 517). He aquí el error, pues esta pereza lo único que trae consigo es que el individuo no piense por sí mismo, sino que asuma las cosas sin plantearse su veracidad. Unamuno reivindicaba, frente al sentido común que impera en estas personas, el sentido propio, aquel que "coge los lugares comunes, los del sentido común, y los convierte, nada más que al apropiárselos, en lugares propios, esto es, en paradojas" (Unamuno, 1914a: 307). Vuelve a poner de manifiesto la centralidad del hombre en toda su reflexión filosófica, obligándolo a pensar y meditar desde su propia circunstancia vital, y no permitiéndole aceptar los pensamientos ajenos y abstractos que se le ofrecen sin evaluarlos por sí mismo. De este modo jugaba a provocar a su público, de modo que los obligaba a pensar, a plantearse las cosas que leían para así proceder con una actitud crítica (Unamuno, 1914a: 307). 
La filosofía no se hace con el sentido común, porque éste enjuicia con los medios ordinarios y comunes del conocimiento, buscando siempre un propósito o fin práctico, lo que le inhabilita para constituirse como un verdadero filosofar. Para que éste sea posible deberá recurrirse a la paradoja como la manera de corregir esas ramplonerías y simplezas que se obtienen mediante el uso del sentido común. Esta noción era vital en su modo de filosofar, porque era parte de su método personal de reflexionar, lo guiaba en su razonar permitiéndole distinguir entre el sentido común y el sentido propio, argumentando que:

[...] el lenguaje común, en efecto, es el del sentido común, formado por las necesidades prácticas de la vida y enderezado a servirlas. No es cosa suya la precisión científica por lo cual tiene la ciencia que empezar por formarse un lenguaje propio y hasta una especie de álgebra [...] El sentido común tiene [...] su campo, que no es precisamente el filosófico; pero la paradoja tiene también el suyo. Y si aquel es lo colectivo, lo común, este es o empieza por ser lo individual, lo propio. La paradoja es el más genuino producto del sentido propio. Y es, por tanto, el más eficaz elemento del progreso, ya que por lo individual se progresa (Unamuno, 1910b: 550-551).

Percibimos que su método filosófico le permite pensar y meditar personalmente, alejándolo de la pereza que caracteriza a aquéllos que se dejan llevar por el sentido común. La paradoja se convirtió en algo esencial en su pensamiento, quizá porque se vio ante la necesidad de defenderse de los que trataban de ultrajarle llamándole "paradojista". No obstante, responderá a la pregunta de qué es la paradoja diciendo que es "una palabra que han inventado los tontos para llamar con ella a todo aquello que oyen por primera vez" (Unamuno, 1908b: 402). Para él, constituía el modo más eficaz para lograr que la verdad fuese accesible al pueblo (Unamuno, 
1906b: 891), puesto que por sí mismo no era capaz de llegar a ella. Esta concepción sobre la paradoja le servía para polemizar con sus detractores recurriendo al sentido mismo de la paradoja, señalando que lo que les ocurría es que simplemente no comprendían lo que decía, y que ni se detenían a intentar entenderlo. Advertía que había que tener cuidado con ellas, porque lo que hoy son paradojas se podían convertir (y de hecho se convierten) en los lugares comunes del mañana (Unamuno, 1915b: 352), ya que en el momento en que la paradoja quedaba libre de aquel que la creó podía convertirse en ese saber vulgar y común al que los perezosos recurren por su apatía. La paradoja, entonces, se torna en un método vital para despertar a las mentes adormecidas.

\section{Originalidad y verdad}

En relación con esto surge el tema de la originalidad. Unamuno pensaba que "la originalidad no consiste en decir algo que antes no haya dicho otro — cosa bastante fácil — sino en combinar y relacionar de una manera personal y propia los pensamientos de común acervo" (1907a: 1306). La idea no es de aquel que la tiene, sino que pertenece a "quien le dio su expresión más adecuada y la colocó entre las demás ideas, sus compańeras en el complejo y contexto donde adquiere su valor todo. La originalidad es eso. No acuñar moneda nueva sino saber usarla" (Unamuno, 1910a: 372). Se sigue consolidando la prioridad del hombre, de cada hombre concreto, a la hora de pensar. Porque no se busca una originalidad que sea una creación desde la nada, sino que se aspira encontrar nuevas relaciones entre las cosas, relaciones nunca antes vistas. Esta originalidad que defiende va a estar enfrentada a las ideas, porque pensaba que tenía más valor el modo de exponerlas que las ideas mismas (Unamuno, 1911: 287), en el entendido de que éstas sólo constituyen la materia prima con la que han de operar las ciencias (Unamuno, 
1904a: 1135). Debe haber un buen uso de las ideas en los hombres, pues no deben tomarlas sin antes haberlas comprendido:

[...] una idea es verdaderamente verdadera en aquel espíritu que es su mundo propio, donde consuena con las demás ideas y surge de ellas; en todo otro espíritu es mentira. Sólo es verdadera una idea con verdad viva, y no muerta, en aquel espíritu que o la engendra o se la hace suya, carne de su carne (Núńez y Ribas, 1896: 159).

Para que una idea sea verdadera ha de ser perfectamente entendida por cada hombre, e integrada en la totalidad de su vida. Una verdad sólo será realmente operativa en nosotros cuando, a pesar de haberla olvidado, se haya convertido en un hábito inconsciente. Sólo así la poseeremos de veras (Unamuno, 1895: 843). Esto significa que hay que interiorizarla para que sea legítima, ya que al hacerlo es cuando la podemos utilizar efectivamente. Si no lo hacemos así, entonces será ineficaz. Por esta misma razón dirá que la verdad hay que saberla, porque con sólo decirla no basta (Unamuno, 1921: 453).

Para comprender el concepto de "verdad" unamuniano vamos a analizar, brevemente, las dos concepciones tradicionales de verdad. La primera de ellas es la concepción griega que la concebía como "descubrimiento". Esto significa que hay que ir desvelando el ser que se halla oculto por el velo de las apariencias. El hombre debe ir revelando el ser oculto, y buscar así la verdad que se esconde bajo la constante transformación y cambio de la realidad. En la segunda, la escolástica, se define a la verdad como una correspondencia entre la cosa y el intelecto, y sólo habría verdad cuando esto se cumpliera (Ferrater, 1994: 3660-3661). Entonces, ¿qué clase de verdad es la que busca Unamuno? Para definirla dirá que:

[...] la verdad es objetiva y subjetiva. Objetivamente es la verdad la relación de las cosas con la gloria de Dios, así como la razón su 
correspondencia con la mente divina y subjetivamente es su relación con nuestra salvación. Es verdadero cuanto glorifica a Dios (todo) y cuanto nos conduce a nuestra salvación en cuanto a ella nos conduce. Todo es, pues, verdadero y la mentira nada positivo (Unamuno, 1970: 782).

Esta definición se escinde en dos, como vemos. Por una parte, la verdad objetiva sería la correspondencia del mundo y Dios, y de la razón y la mente divina. Por otro lado, la verdad subjetiva vendría dada por la relación de Dios con nuestra salvación. Esto nos sugiere que la máxima aspiración del hombre es Dios, al que podemos acceder gracias a la semejanza de nuestra razón con la mente divina, ya que podemos conocerlo mediante el conocimiento del mundo. Esto puede ser así porque es Dios quien nos confiere la finalidad de la vida, que es nuestra salvación. Por tanto, la concepción unamuniana de la verdad sería una fusión entre las dos formas de verdad a las que antes aludíamos. Por un lado, sería imprescindible la adecuación entre Dios-Mundo-Hombre. Pero a la vez debe haberse producido en todo hombre un "descubrimiento" interior, de forma que la verdad sea operativa en él por haberla hecho hábito. Y es que Unamuno no entendía eso de la verdad por la verdad, afirmando que era algo inhumano. El punto de partida de todo filosofar ha de tener un para qué, pues el filósofo debe teorizar con un fin (Unamuno, 1913a: 126).

Podemos decir que la verdad ha de ser lo esencial en la vida de cada hombre, pues ella es la que nos conduce y nos permite engrandecer nuestro espíritu: "buscar la vida en la verdad, es, pues, buscar en el culto de esta ennoblecer y elevar nuestra vida espiritual y no convertir a la verdad, que es, y debe ser siempre viva, en un dogma, que suele ser una cosa muerta” (Unamuno, 1908a: 267).

Para Unamuno es evidente la íntima relación existente entre verdad y vida, afirmando que el fin de su vida es la búsqueda de la verdad, a pesar de estar seguro de no poder encontrarla nunca 
(Unamuno, 1907b: 260). Así, esta vinculación tiene que ser capaz de ayudar al hombre en su vivir. Es muy significativo el lema unamuniano que reza "antes la verdad que la paz" (Unamuno, 1909: 269), y que podría resumir no sólo su pensamiento, sino también su vida.

Ella es la que nos hace vivir, y no lo que nos hace pensar (Unamuno, 1905: 210). Por esto llegará a afirmar que la inteligencia ha de estar a su servicio, pues le corresponde hallar la verdad, pero el encontrarla será mediante la crítica, pues si no será imposible alcanzarla (Unamuno, 1923b: 671). Urrutia, al respecto, apunta:

[...] la verdad no la penetran ni el instinto ni el sentimiento, la verdad es cosa de la razón. Y hasta las que llamamos verdades de sentimiento, o de fe, no son verdades, sino cuando la razón las aprende. Es la razón la que hace verdadero el sentimiento (1970: 303).

Por tanto, vemos cómo la verdad está supeditada a la razón, aún cuando anteriormente hemos visto cómo reconocía el estatuto ontológico de diversos modos de realidad. Esto significaba que aceptaba y defendía otro tipo de razón que no fuese la lógico-matemática que tendría que adaptarse a esos otros modos de presentarse la realidad. Afirmaba que lo que había que buscar no era la razón de las cosas, sino la verdad (Unamuno, 1970: 777).

Por tanto, podemos concluir afirmando que sí existe una reflexión acerca del conocimiento en el pensamiento unamuniano. Lo que ocurre es que no la hallaremos formulada de manera explícita en su obra. Sin embargo, vemos cómo planteaba una forma de acceder a la realidad caracterizada, de modo primordial, por su relación con el hombre concreto. Sólo el individuo, mediante la palabra y ayudado de la intuición, podrá tener pleno conocimiento de un mundo esencialmente histórico y mudable. 


\section{Bibliografía}

Aristóteles, 1975, Metafísica, Austral, Madrid.

Descartes, R., 1997, Meditaciones metafísicas, Austral, Madrid.

Ferrater Mora, J., 2005, Diccionario de Filosofía, RBA, Barcelona.

Grassi, E., 2003, El poder de la fantasía, Anthropos, Barcelona.

Guthrie, W. K. C., 1990, Historia de la Filosofía Griega, Gredos, Madrid.

Montaño, L., y J. Sánchez, 2006, "Humanismo retórico, viquismo y unamunismo", en Cuadernos sobre Vico, núm. 17-18, Sevilla, pp. 377-386.

Núñez, D., y Ribas, P., (1896) 1997, "Verdadera caridad”, en Unamuno y el socialismo: artículos recuperados, Comares, Granada.

__, 1902, "Un artículo", en Unamuno y el socialismo: artículos recuperados, Comares, Granada, 1997.

__, 1911, "La mentira religiosa", en Unamuno y el socialismo: artículos recuperados, Comares, Granada, 1997.

__, 1923, "La fiesta de la raza”, en Unamuno y el socialismo: artículos recuperados, Comares, Granada, 1997.

Serrano, J. M., 1994, "Unamuno frente a Descartes, Spinoza y Kant", en Cuadernos de la Cátedra Miguel de Unamuno, vol. 39, 1, Salamanca, pp. 143-167.

Unamuno, Miguel de (1886), 1966, "Del elemento alienígena en el idioma vasco", en Obras Completas (O. C.), v. IV, Escelicer, Madrid.

—_, (1895), 1966, "De mística y humanismo”, en O. C., v. I, Escelicer, Madrid.

__, (1900), 1970, “La leyenda del eclipse”, en O. C., v. VIII, Escelicer, Madrid.

—, (1902a), 1970, “De vuelta”, en O. C. v. VIII, Escelicer, Madrid. 
—_, (1902b), 1966, "La cuestión del vascuence", en O. C., v. I, Escelicer, Madrid.

_ , (1903a), 1971, "Conferencia pronunciada en el teatro principal de La Coruña la noche del 18 de junio de 1903, a invitación de la Reunión de artesanos de dicha ciudad", en $O$. C., v. IX, Escelicer, Madrid.

__(1903b), 1966, “La selección de los fulánez”, en O. C., v. I, Escelicer, Madrid.

—_, (1904a), 1966, "La locura del doctor Montarco", en O. C., v. I, Escelicer, Madrid.

—, (1904b), 1966, "Sobre la filosofía española”, en O. C., v. I, Escelicer, Madrid.

—, (1905), 1968, Vida de Don Quijote y Sancho, O. C., v. III, Escelicer, Madrid.

—, (1906a), 1968, "El secreto de la vida", en O. C., v. III, Escelicer, Madrid.

—, (1906b), 1968, "Sobre la consecuencia, la sinceridad", en O. C., v. III, Escelicer, Madrid.

—_, (1906c), 1971, "La enseñanza de la gramática”, en O. C., v. IX, Escelicer. Madrid.

—, (1907a), 1969, "La feliz ignorancia", en O. C., v. VII, Escelicer, Madrid.

—, (1907b), 1968, "Mi religión”, en O. C., v. III, Escelicer, Madrid.

—_, (1907c), 1968, "Soliloquio", en O. C., v. III, Escelicer, Madrid

—_, (1908a), 1968, "Verdad y vida”, en O. C., v. III, Escelicer, Madrid.

—_, (1908b), 1968, "Divagaciones de estío", en O. C., v. III, Escelicer, Madrid.

—, (1909), 1968, "De la correspondencia de un luchador", en $O$. C., v. III, Escelicer, Madrid. 
—_ (1910a), 1968, "Conversación primera", en O. C., v. III, Escelicer, Madrid.

—, (1910b), 1968, "Un filósofo del sentido común”, en O. C., v. III, Escelicer, Madrid.

—_, (1911, 1970, "El desinterés intelectual”, en O. C., v. VIII, Escelicer, Madrid.

— (1912), 1969, "Cuestiones del momento", en O. C., v. VII, Escelicer, Madrid.

—_, (1913a), 1969, Del sentimiento trágico de la vida, O. C., v. VII, Escelicer, Madrid.

——, (1913b), 1970, "Sobre mí mismo”, en O. C., v. VIII, Escelicer, Madrid.

—_, (1914a), 1970, "Manuel Machado y yo”, en O. C. VIII, Escelicer, Madrid.

—, (1914b), 1970, "Arabesco pedagógico sobre el juego", en O. C., v. VIII, Escelicer, Madrid.

__ (1915a), 1971, "Lo que puede aprender Castilla de los poetas catalanes”, en $O$. C., v. IX, Escelicer, Madrid.

— (1915b), 1970, "Mis paradojas de antaño", en O. C., v. VIII, Escelicer, Madrid.

—, (1916), 1970, Prólogo a la obra Orígenes del conocimiento. (El hambre) de R. Turró, en O. C., v. VIII, Escelicer, Madrid, pp. 1084-9.

—, (1917), 1968, "Vida e historia”, en O. C., v. III, Escelicer, Madrid.

— (1921), 1970, “Diario de un azulado", en O. C., v. VIII, Escelicer, Madrid.

—, (1922), 1969, "Escritura y lenguaje", en O. C., v. VII, Escelicer, Madrid.

— (1923a), 1970, "Pirandello y yo", en O. C., v. VIII, Escelicer, Madrid. 
— Madrid.

—_, (1927), 1970, Cómo se hace una novela, O. C., v. VIII, Escelicer, Madrid.

—_, (1931), 1969, La agonía del cristianismo, O. C., v. VII, Escelicer, Madrid.

—, (1932), 1970, "En confidencia”, en O. C., v. VIII, Escelicer, Madrid.

—, (1936), 1969, "Hincar codos", en O. C. VII, Escelicer, Madrid.

—, 1970, Diario intimo, O. C., v. VIII, Escelicer, Madrid.

— 1986, Cartas intimas (ed. de Javier González Durana), Eguzki Argitaldaria, Bilbao.

—_, 1991, Epistolario inédito, vol. II (ed. de Laureano Robles), Espasa Calpe, Madrid.

—_, 1997, De patriotismo espiritual (ed. de Víctor Ouimette), Editorial Sígueme, Salamanca.

—_, 1998, Escritos inéditos sobre Euskadi (ed. de Laureano Robles), Monografías Bidebarrieta, Bilbao.

Urrutia, L., 1970, Desde el mirador de la guerra, Institut d'etudes Hispaniques, París.

Urrutia, M. Ma, 2006, "La colaboración de Unamuno en El Liberal de Madrid", en Cuadernos de la Cátedra Miguel de Unamuno, vol. 41,1, Salamanca, pp. 213-282. 